\title{
Cationic Polymerization of Anethole and Its Model Reaction: A Stereochemical Approach to the Propagation Mechanism
}

\author{
Toshinobu Higashimura, ${ }^{* 1}$ Yoshitsugu HiroKawa, ${ }^{* 1}$ Kei MatsuZaki, ${ }^{* 2}$ \\ Tokiji KaWAMURA, ${ }^{* 2}$ and Toshiyuki URYU*2 \\ ${ }^{* 1}$ Department of Polymer Chemistry, Faculty of Engineering, \\ Kyoto University, Kyoto 606, Japan. \\ *2 Department of Industrial Chemistry, Faculty of Engineering, \\ University of Tokyo, Hongo, Bunkyo-ku, Tokyo 113, Japan.
}

(Received June 20, 1979)

\begin{abstract}
The stereochemistry in the cationic polymerization of anethole, a $\beta$-substituted styrene, was investigated to clarify the propagation mechanism. The addition of acetaldehyde dimethyl acetal to anethole (acetal addition) was also studied as a model reaction. ${ }^{13} \mathrm{C}$ NMR spectra showed that trans-anethole gave stereoregular polymers and that cis-isomer did not, indicating that the steric structure of the polymers depended on the geometrical structure of the monomer rather than on the polymerization conditions employed. On the other hand, the stereospecificity of the acetal addition was not very high even in the best case with trans-anethole ( $76 \%$ specificity). These results suggest that the structure of the attacking carbocation plays an important role in controlling the steric structure of products.

KEY WORDS Anethole / Cationic Polymerization / Acetal Addition / Stereochemistry $/{ }^{13} \mathrm{C}$ NMR Spectra /
\end{abstract}

It has been shown that in the cationic polymerization of $\beta$-substituted vinyl ethers, the steric interaction between the substituents of a propagating chain end and of a monomer plays an important role in determining the steric structure of polymers. ${ }^{1-4}$ Vinyl ethers possess flexible ethereal linkages adjacent to the double bond. On the other hand, styrene derivatives 'bear rigid aromatic rings that are attached directly to double bonds through branched $\alpha$ carbons. Therefore, it is expected that the steric interaction between substituents in the propagation process of the styrene derivatives is different from that of vinyl ethers.

The effect of introducing a $\beta$-methyl group to vinyl ethers on their reactivity ${ }^{5-7}$ and on the stereochemistry $^{1-4}$ of their polymerization has been investigated so as to be able to discuss the propagation mechanism. However, to date, there has been no stereochemical study with $\beta$-substituted styrenes because of the complicated ${ }^{1} \mathrm{H}$ NMR spectra of their polymers. Such a study should be helpful for gaining further insight into the steric course and mechanism of the propagation process in cationic polymerization.
The present work deals with the stereochemistry of cationic polymerization of anethole, a $\beta$-substituted styrene derivative, and its reaction. with an acetal (acetal addition) as a model process. The steric structures of resultant polymers and acetal adducts were determined by ${ }^{13} \mathrm{C}$ and ${ }^{1} \mathrm{H}$ NMR spectroscopy. The usefulness of stereochemical analysis of the acetal adducts has already been demonstrated. ${ }^{8,9}$ Anethole was employed as the monomer because of its high cationic polymerizability due to the electrondonating $p$-methoxy group.

\section{EXPERIMENTAL}

\section{Materials}

cis-Anethole was synthesized by the decarboxylation of $p$-methoxy- $\beta$-methylcinnamic acid prepared from $p$-anisaldehyde and propionic anhydride by Perkin reaction. ${ }^{10,11}$ cis-Anethole thus obtained and commercial trans-anethole were purified by distillation over $\mathrm{CaH}_{2}$. Geometrical purities were found to be $98 \%$ for the cis-isomer and more than $99 \%$ for the trans-isomer by means of gas chromatography. 
<smiles>CC=Cc1ccc(OC)cc1</smiles>

(1)<smiles>COc1ccc(C(C)C(C)OC)cc1</smiles>

(2)<smiles>COc1ccc(C(C)C(C)OC)cc1</smiles>

(3)

Scheme I

Commercial acetaldehyde dimethyl acetal was purified by distillation over metal sodium. Solvents $\left(\mathrm{C}_{6} \mathrm{H}_{5} \mathrm{CH}_{3}\right.$ and $\left.\mathrm{CH}_{2} \mathrm{Cl}_{2}\right)$ were purified as described previously. ${ }^{3}$ Catalysts $\left[\mathrm{SnCl}_{4}\right.$ and $\mathrm{BF}_{3} \mathrm{O}\left(\mathrm{C}_{2} \mathrm{H}_{5}\right)_{2}$ ] were purified by distillation. Acetyl perchlorate $\left(\mathrm{CH}_{3} \mathrm{COClO}_{4}\right)$ was prepared as reported elsewhere. $^{12}$ Trichloroacetic acid (TCA) (Guaranteed Reagent) as a cocatalyst for $\mathrm{SnCl}_{4}$ was used without further purification. A half molar quantity of TCA was always employed and this catalyst system is referred to as $\mathrm{SnCl}_{4}-(1 / 2)$ TCA.

\section{Procedures}

Polymerizations were carried out under dry nitrogen. The conversion was determined by the amount of residual monomer measured by gas chromatography. The polymers produced were precipitated into excess methanol, filtered off, and dried under vacuum. Their molecular weights were measured by gel-permeation chromatography (GPC) on the basis of a calibration curve for polystyrene.

Acetal addition between acetaldehyde dimethyl acetal and anethole was performed as shown in Scheme I. After a solution of $\mathrm{BF}_{3} \mathrm{OEt}_{2}$ in $\mathrm{CH}_{2} \mathrm{Cl}_{2}$ had been added to an acetal and the mixture had stood at $0^{\circ} \mathrm{C}$ for a short time, the reaction was started by the addition of anethole at $0^{\circ} \mathrm{C}$ under dry nitrogen. After a certain time, it was stopped by the addition of ammoniacal methanol. ${ }^{9}$ The $1: 1$ adduct was isolated from the crude product by preparative liquid chromatography.

${ }^{13} \mathrm{C}$ NMR spectra $25.03 \mathrm{MHz}$ of the polymers were measured in $\mathrm{CDCl}_{3}$ at $60^{\circ} \mathrm{C}$ by use of a JEOL-
PS-100 NMR spcetrometer. ${ }^{1} \mathrm{H}$ and ${ }^{13} \mathrm{C}$ NMR spectra of the adduct were obtained in $\mathrm{CDCl}_{3}$ at $24^{\circ} \mathrm{C}$ on Varian HA-100 and JEOL FS-60 spectrometers, respectively. Tetramethylsilane was used as an internal reference.

\section{RESULTS AND DISCUSSION}

Steric Structure of Poly(anethole)s

cis- and trans-Anetholes were polymerized with $\mathrm{SnCl}_{4}-(1 / 2) \mathrm{TCA}$ in $\mathrm{C}_{6} \mathrm{H}_{5} \mathrm{CH}_{3}$ or $\mathrm{CH}_{2} \mathrm{Cl}_{2}$. $\mathrm{CH}_{3} \mathrm{COClO}_{4}$ was also used as catalyst for comparison. All reactions gave white powdery polymers which were mostly insoluble in methanol and soluble in $\mathrm{CHCl}_{3}$, although the product obtained at $0^{\circ} \mathrm{C}$ contained a methanol-soluble fraction (less than 20 $\mathrm{wt} \%$ ) and those formed at $-78^{\circ} \mathrm{C}$ contained small amounts of material insoluble in such organic solvents as $\mathrm{C}_{6} \mathrm{H}_{5} \mathrm{CH}_{3}, \mathrm{CHCl}_{3}$, and $o-\mathrm{C}_{6} \mathrm{H}_{4} \mathrm{Cl}_{2}$. In this work, the methanol-insoluble and $\mathrm{CHCl}_{3}$-soluble polymer were studied.

${ }^{13} \mathrm{C}$ NMR spectra of the polymers obtained from cis- and trans-anetholes are shown in Figures 1 and 2, respectively, which also indicate peak assignments made by reference to those for polystyrene ${ }^{13}$ and poly ( $p$-methoxystyrene $)^{14}$ as well as by an empirical method.$^{15}$ In Figure 1, the spectra $\mathrm{A}-\mathrm{C}$ are arranged in order of increasing peak intensity at $c a .140$ ppm; in Figure 2 the spectra $D-G$ are given in order of increasing stereoregularity of the polymers (see below). Table I shows relative peak intensities based on the peak area. The observed values were in good agreement with the theoretical values, indicating the 


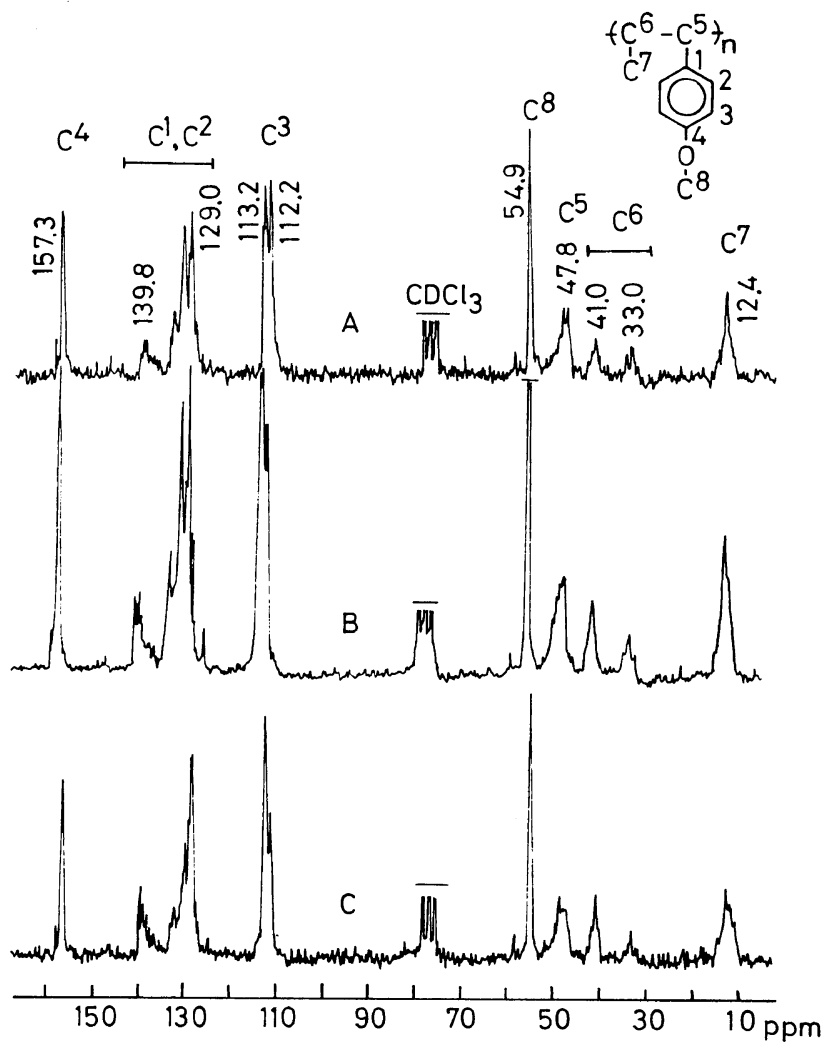

Figure 1. ${ }^{13} \mathrm{C}$ NMR spectra of poly(cis-anethole)s obtained with $\mathrm{SnCl}_{4}-(1 / 2) \mathrm{TCA} ;[\mathrm{M}]=10$ vol $1 \%$.

\begin{tabular}{ccccccc}
\hline Run & Solvent & {$[\mathrm{C}] / \mathrm{mmol} \mathrm{dm}^{-3}$} & $\mathrm{Temp} /{ }^{\circ} \mathrm{C}$ & Time $/ \mathrm{min}$ & Conversion/\% & $\begin{array}{c}\text { molecular } \\
\text { weight }{ }^{\mathrm{a}}\end{array}$ \\
\hline A & $\mathrm{C}_{6} \mathrm{H}_{5} \mathrm{CH}_{3}$ & 30.0 & 0 & 45 & 34 & 2800 \\
B & $\mathrm{C}_{6} \mathrm{H}_{5} \mathrm{CH}_{3}$ & 30.0 & -30 & 60 & 55 & 4000 \\
$\mathrm{C}$ & $\mathrm{CH}_{2} \mathrm{Cl}_{2}$ & 10.0 & 0 & 30 & 35 & 2700 \\
\hline
\end{tabular}

a By GPC.

propriety of the assignment.

The spectra of poly(trans-anethole) consisted mostly of sharp absorptions for individual carbons irrespective of the solvents and catalyst used (Figure 2). Poly(cis-anethole), on the other hand, showed doublets for carbons $C^{1}$ (140 and 130 ppm), $C^{3}$ (113 and $112 \mathrm{ppm}$ ), and $\mathrm{C}^{6}$ (41 and $\left.33 \mathrm{ppm}\right)$. The intensity ratio of the two peaks of each doublet depended on polymerization conditions. These facts indicate that a stereoregular polymer was obtained from the transmonomer, but not from the $c i s$-monomer. ${ }^{13} \mathrm{C}$ NMR spectroscopy has thus enabled us, for the first time, to discuss the stereoregularity of poly(anethole).

Table II shows the intensity ratios of the doublets due to $\mathrm{C}^{1}, \mathrm{C}^{3}$, and $\mathrm{C}^{6}$ carbons. For each polymer obtained from the cis-monomer, the three carbons gave nearly the same ratios, suggesting that $\alpha$ - and $\beta$ carbons of the main chain have the same configuration.

It should be mentioned that the split peaks did not result from a structural irregularity such as deviation from the regular head-to-tail enchainment that is sometimes observed in anethole polymerization, ${ }^{16}$ since in such a case, the three carbons would show 

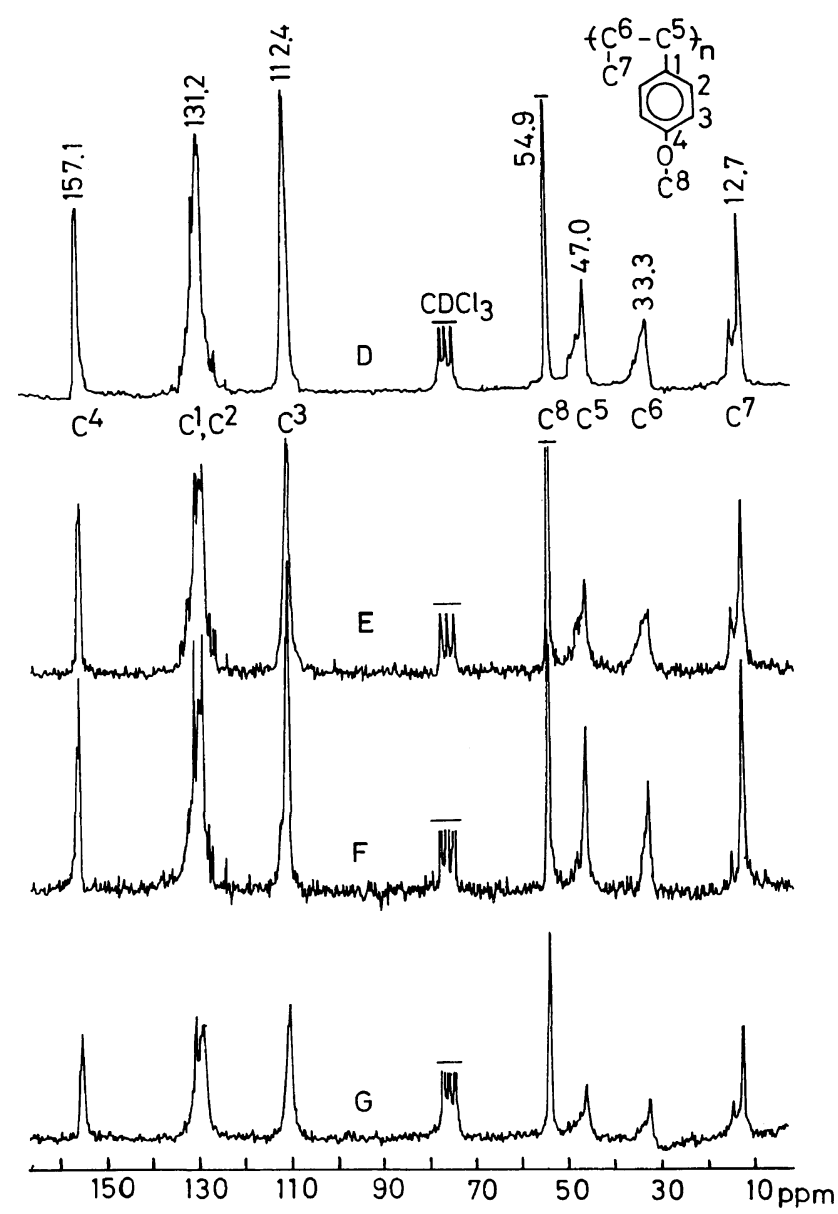

Figure 2. ${ }^{13} \mathrm{C}$ NMR spectra of poly(trans-anethole)s obtained with $\mathrm{SnCl}_{4}-(1 / 2) \mathrm{TCA} ;[\mathrm{M}]=$ $10 \mathrm{vol} \%$.

\begin{tabular}{llrrrrr}
\hline Run & Solvent & {$[\mathrm{C}] / \mathrm{mmol} \mathrm{dm}^{-3}$} & $\mathrm{Temp} /{ }^{\circ} \mathrm{C}$ & Time $/ \mathrm{min}$ & $\begin{array}{c}\text { Conversion } / \% \\
\text { Molecular } \\
\text { weight }^{\mathbf{a}}\end{array}$ \\
\hline $\mathrm{D}$ & $\mathrm{C}_{6} \mathrm{H}_{5} \mathrm{CH}_{3}$ & 30.0 & 0 & 10 & 55 & 6700 \\
$\mathrm{E}$ & $\mathrm{C}_{6} \mathrm{H}_{5} \mathrm{CH}_{3}$ & 30.0 & -30 & 15 & 70 & 33000 \\
$\mathrm{~F}$ & $\mathrm{CH}_{2} \mathrm{Cl}_{2}$ & 10.0 & 0 & 10 & 89 & - \\
$\mathrm{G}^{\mathrm{b}}$ & $\mathrm{C}_{6} \mathrm{H}_{5} \mathrm{CH}_{3}$ & 10.0 & -78 & 11 & 60 & - \\
\hline
\end{tabular}

${ }^{a}$ By GPC. ${ }^{b}$ Catalyst, $\mathrm{CH}_{3} \mathrm{COClO}_{4}$.

different intensity ratios.

In the cationic polymerization of trans- $\beta$ substituted vinyl ethers, ${ }^{5,17}$ it has been concluded that the direction of addition of the propagating species is limited on account of considerable steric hindrance of the two substituents placed on both sides of the double bond, resulting in the preferential production of polymers with one steric structure, namely stereoregular polymers. This can also explain the formation of stereoregular polymers from transanethole. On the other hand, cis-anethole which holds its two substituents on one side of the double bond may permit the propagating species to approach from two directions, giving nonstereoregular 
Table I. ${ }^{13} \mathrm{C}$ NMR peak intensities of poly(anethole) $\mathrm{s}^{\mathrm{a}}$

\begin{tabular}{|c|c|c|c|c|c|c|c|c|c|}
\hline \multirow{2}{*}{ Run $^{a}$} & $\mathrm{C}^{4}$ & \multicolumn{2}{|c|}{$\mathrm{C}^{1}, \mathrm{C}^{2}$} & \multirow{2}{*}{$\frac{C^{3}}{114-110}$} & \multirow{2}{*}{$\frac{C^{8}}{55-54}$} & \multirow{2}{*}{$\frac{C^{5}}{50-46}$} & \multicolumn{2}{|c|}{$C^{6}$} & \multirow{2}{*}{$\frac{C^{7}}{15-10}$} \\
\hline & $159-156 \mathrm{ppm}$ & $141-138$ & $135-126$ & & & & $42-40$ & $35-32$ & \\
\hline $\begin{array}{l}\text { Expected } \\
\text { Intensity }\end{array}$ & $\begin{array}{c}10.0 \% \\
---\end{array}$ & $\begin{array}{r}30 . \\
-\quad-\quad-\end{array}$ & $0 \%$ & $\begin{array}{l}20.0 \% \\
---\end{array}$ & $\begin{array}{c}10.0 \% \\
-\quad-\end{array}$ & $\begin{array}{l}10.0 \% \\
---\end{array}$ & $\begin{array}{r}10 \\
---\end{array}$ & $\%$ & $\begin{array}{l}10.0 \% \\
-\quad-\end{array}$ \\
\hline A & 7.8 & 5.0 & 25.3 & 21.7 & 10.4 & 9.7 & 4.7 & 5.2 & 10.2 \\
\hline B & 8.9 & 6.1 & 26.0 & 21.7 & 10.9 & 8.2 & 4.6. & 4.0 & 9.6 \\
\hline $\mathrm{C}$ & 7.7 & 6.5 & 26.5 & 21.5 & 10.4 & 8.2 & 5.6 & 3.4 & 10.2 \\
\hline D & 8.4 & - & 31.4 & 21.8 & 10.9 & 8.9 & - & 8.4 & 10.2 \\
\hline $\mathrm{E}$ & 8.5 & - & 29.9 & 19.0 & 12.4 & 9.2 & - & 10.1 & 10.9 \\
\hline $\mathrm{F}$ & 8.7 & - & 30.2 & 21.0 & 11.9 & 8.9 & - & 8.6 & 10.7 \\
\hline $\mathrm{G}$ & 8.0 & - & 29.3 & 21.1 & 11.9 & 9.3 & - & 8.4 & 12.0 \\
\hline
\end{tabular}

${ }^{a}$ For symbols and reaction conditions, see Figures 1 and 2.

Table II. Relative ${ }^{13} \mathrm{C}$ NMR peak intensities of poly(anethole)s

\begin{tabular}{|c|c|c|c|c|}
\hline \multirow{2}{*}{$\operatorname{Run}^{\mathrm{a}}$} & \multirow{2}{*}{ Monomer } & \multicolumn{3}{|c|}{ (Low field/High field) } \\
\hline & & $\mathrm{C}^{1}$ & $\mathrm{C}^{3}$ & $\mathrm{C}^{6}$ \\
\hline A & cis & $50 / 50$ & $47 / 53$ & $48 / 52$ \\
\hline B & $"$ & $57 / 43$ & $57 / 43$ & $54 / 46$ \\
\hline $\mathrm{C}$ & $"$ & $59 / 41$ & $60 / 40$ & $62 / 38$ \\
\hline $\mathrm{D}$ & trans & $0 / 100$ & $0 / 100$ & $0 / 100$ \\
\hline E & $"$ & $0 / 100$ & $0 / 100$ & $0 / 100$ \\
\hline $\mathrm{F}$ & $"$ & $0 / 100$ & $0 / 100$ & $0 / 100$ \\
\hline G & , & $0 / 100$ & $0 / 100$ & $0 / 100$ \\
\hline
\end{tabular}

a Symbols are the same as in Figures 1 and 2.

polymers as in the polymerization of cis-propenyl ethers.

For poly(trans-anethole)s, the width of the singlets, the decrease of which reflects an increase in the polymer stereoregularity, depended clearly on polymerization conditions, as seen in Figure 2. The polymer stereoregularity increased as the solvent polarity increased in the polymerization by $\mathrm{SnCl}_{4}-(1 / 2) \mathrm{TCA}$, and the polymer obtained with $\mathrm{CH}_{3} \mathrm{COClO}_{4}$ at $-78^{\circ} \mathrm{C}$ showed the sharpest peaks (Figure 2G). An increase in stereoregularity with increasing solvent polarity was also observed for poly(cis-anethole)s (Table II). Since the counterion resides apart from the propagating carbocation in polar solvents such as $\mathrm{CH}_{2} \mathrm{Cl}_{2}$, the above results suggest that, in the polymerization of $\beta$-substituted vinyl monomers (e.g., anethole and propenyl ethers), the predominant factor determining the steric structure of polymers is not the presence of the counterion, but the interaction between the substituents of the propagating end and the approaching monomer.

\section{Acetal Addition to Anethole}

The steric structure of poly(anethole) was found to depend on the geometrical structure of the monomer and polymerization conditions. The above NMR analysis of the polymers, however, could not identify the configuration of their backbones and this is necessary for discussing the propagation mechanism in detail. Therefore, the steric structure of acetal adducts of anethole, which is regarded as stereochemical model compounds for the anethole polymerization, was then examined by ${ }^{13} \mathrm{C}$ and ${ }^{1} \mathrm{H}$ NMR spectroscopy. The addition of acetaldhyde dimethyl acetal to anethole proceeded as follows.

Although the carbocation 1 produced from the acetal is different in structure from the propagating poly(anethole) cation, it may be possible to discuss the direction of cation addition to anethole on the basis of the steric structure of the adduct 3 .

Anethole was treated with acetaldehyde dimethyl acetal in $\mathrm{CH}_{2} \mathrm{Cl}_{2}$ at $0^{\circ} \mathrm{C}$ in the presence of $\mathrm{BF}_{3} \mathrm{O}\left(\mathrm{C}_{2} \mathrm{H}_{5}\right)_{2}$, to yield the $1: 1$ adduct $3(\mathrm{ca} .60 \%)$ and anethole oligomers ( $\mathrm{ca} .40 \%$ ). Figure 3 shows ${ }^{1} \mathrm{H}$ NMR spectra of $1: 1$ adducts obtained from $c i s$ - and trans-anetholes. The peaks were assigned from downfield to aromatic $(\delta 7.3-6.8 \mathrm{ppm})$, methoxyl and their vicinal methine (4.3-2.8 ppm), aliphatic methine (2.4-1.6 ppm), and methyl (1.2-0.5 ppm) 


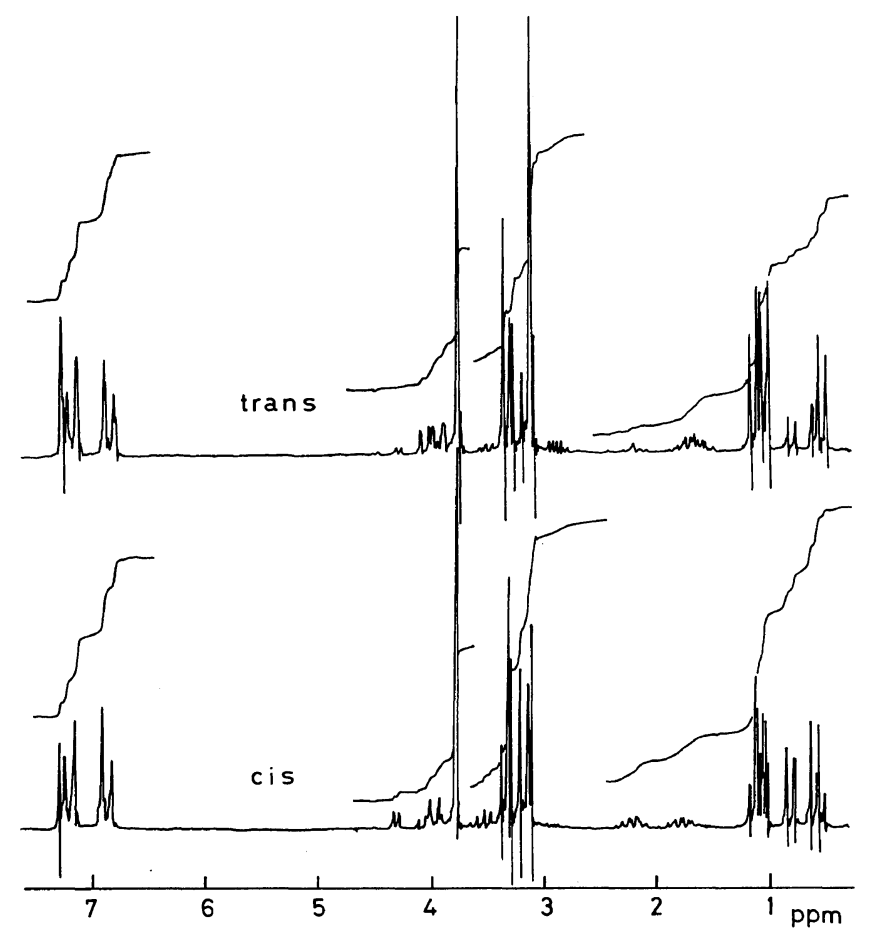

Figure 3. ${ }^{1} \mathrm{H}$ NMR spectra of $1: 1$ adducts of acetaldehyde dimethyl acetal and anethole obtained with $\mathrm{BF}_{3} \mathrm{O}\left(\mathrm{C}_{2} \mathrm{H}_{5}\right)_{2}$ in $\mathrm{CH}_{2} \mathrm{Cl}_{2}$ at $0^{\circ} \mathrm{C} ;[\mathrm{C}]=100 \mathrm{mmoldm}{ }^{-3}$; time, $48 \mathrm{~h}$; conversion, $>99^{\circ}$; acetal/anethole $/ \mathrm{CH}_{2} \mathrm{Cl}_{2}, 3 / 1 / 11$ by volume. Trans and cis indicate the geometrical structure of the starting anethole.

protons, respectively; integral peak intensities were in good agreement with the expected values. Thus, the product was confirmed to be the $1: 1$ adduct 3 .

Expanded ${ }^{1} \mathrm{H}$ and ${ }^{13} \mathrm{C}$ NMR spectra of the head methyl group of $\mathbf{3}$ (underlined in the formula) are shown in Figures 4 and 5, respectively. Since 3 has three asymmetric carbon atoms, it is expected that the possible four stereoisomers of $\mathbf{3}$ might be distinguished by NMR spectroscopy. The ${ }^{1} \mathrm{H}$ and ${ }^{13} \mathrm{C}$ NMR spectra consist of four doublets and four singlets, respectively, so that they must indicate different steric structures of the adduct. The absorption due to the other atoms also showed the same splitting.

Relative ${ }^{13} \mathrm{C}$ NMR peak intensities of the four singlets, which depended on the geometrical structure of the starting anethole, were determined as shown in Table III. Peaks 1 and 2 prevailed for the adduct obtained from the trans isomer whereas peaks 3 and 4 did so for the adduct from the cis isomer. In both adducts, the ratio of the intensity of

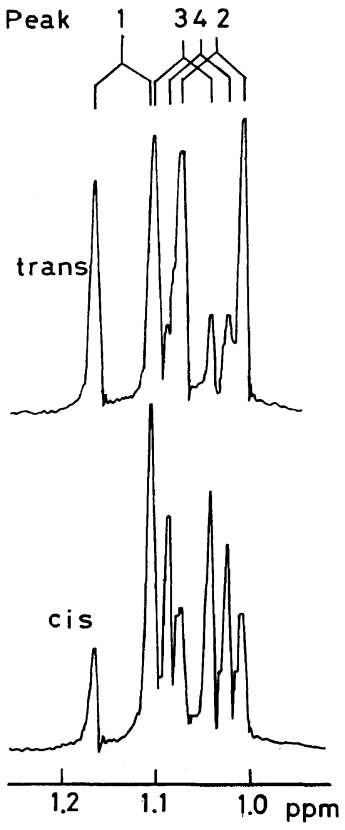

Figure 4. ${ }^{1} \mathrm{H}$ NMR spectra of the head methyl group of the acetal adducts given in Figure 3. 


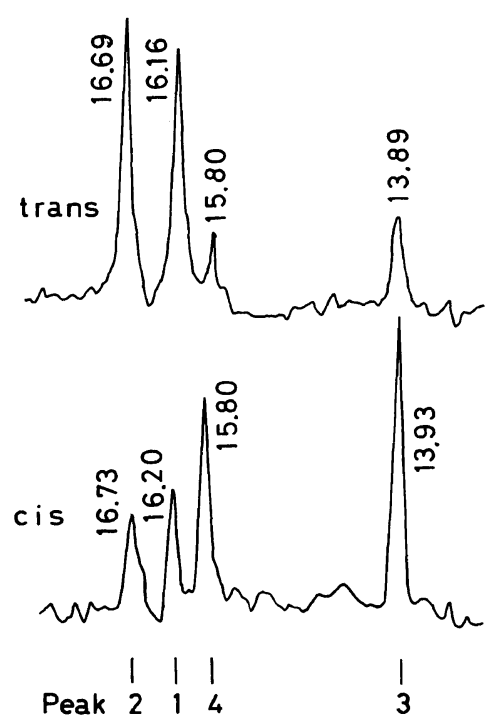

Figure 5. ${ }^{13} \mathrm{C}$ NMR spectra of the head methyl group of the acetal adducts given in Figure 3.

Table III. Relative ${ }^{13} \mathrm{C}$ NMR peak intensities of the head methyl group of the acetal adduct 3

\begin{tabular}{|c|c|c|}
\hline \multirow{2}{*}{ Peak $^{\mathrm{a}}$} & \multicolumn{2}{|c|}{ Relative peak intensity } \\
\hline & $\operatorname{trans}^{\mathrm{b}}$ & $c i s^{\mathrm{b}}$ \\
\hline 1 & 407 & 157 \\
\hline 2 & $36 \int^{10}$ & $19 \int^{J}$ \\
\hline 3 & \multirow{2}{*}{24} & $34)$ \\
\hline 4 & & $32\}^{00}$ \\
\hline
\end{tabular}

a Peak numbers are the same as in Figures 4 and 5.

b Geometrical structure of the starting anethole.

peak 1 to that of peak 3 is almost equal to that of peak 2 to peak 4 , and this shows that two pairs of the distinguishable four stereoisomers are present in nearly equal abundances.

The latter finding indicates that two of the three asymmetric carbon atoms were sterically random; i.e., they were formed nonstereospecifically in the addition reaction. Since one of them is inherently the acetal carbon $\left[\mathrm{CH}_{3}-\stackrel{*}{\mathrm{C}} \mathrm{H}\left(\mathrm{OCH}_{3}\right)-\right]$, it follows that either the addition of the acetal cation 1 [step (i) in Scheme] or that of the methoxide anion [step (ii)] proceeds in a stereochemically random way. We assume a random methoxide addition, or random opening of the double bond, on the basis of the expected longer lifetime of the intermediate 2 that may be resonance-stabilized by its electron-donating $p$-methoxyphenyl group. If this assumption is the case, the total intensity of peaks 1 and 2 or that of peaks 3 and 4 should be proportional to the probability that the acetal cation $\mathbf{1}$ attacks anethole from one particular side of its molecular plane.

The stereospecificity of the addition to transanethole was thus found to be $76 \%$. A lower value $\left(66^{\circ}\right)$ was observed for cis-anethole, which also indicates that the acetal additions to cis- and transanetholes take place from opposite directions. The higher stereospecificity for trans-anethole can be explained, as for trans- $\beta$-substituted vinyl ethers, ${ }^{4}$ by the fact that it carries its two substituents on both sides of the double bond, which may promote addition from one direction. However, the $76 \%$ specificity for trans-anethole is fairly lower than the corresponding value for trans-alkenyl ethers $(90 \%){ }^{4}$ This is due to smaller steric hindrance of the planar benzene ring and the smaller effect of the polar ( $p$ methoxy) group apart from the double bond. The rigid benzene ring directly attached to the reaction site induced no increase in stereospecificity.

The stereospecificity of the acetal addition to anethole, even in the best case with the trans isomer, was not so high as in the corresponding polymerization which produced highly stereoregular poly(trans-anethole), although the steric course of both reactions similarly depended on the geometrical structure of anethole. This probably originates from the different structures of the attacking carbocations, which, therefore, seem to be another important factor in determining the steric structure of polymers.

\section{REFERENCES}

1. G. Natta, J. Polym. Sci., 48, 219 (1960).

2. G. Natta, M. Peralda, M. Farina, and G. Bressan, Makromol. Chem., 55, 139 (1962).

3. T. Higashimura, M. Hoshino, Y. Hirokawa, K. Matsuzaki, and T. Uryu, J. Polym. Sci., Polym. Chem. Ed., 15, 2691 (1977).

4. Y. Hirokawa, T. Higashimura, K. Matsuzaki, and T. Uryu, J. Polym. Sci., Polym. Chem. Ed., 17, 1473 (1979).

5. A. Mizote, S. Kusudo, T. Higashimura, and S. Okamura, J. Polym. Sci., A-1, 5, 1927 (1967); ibid., 6, 2511 (1968). 
6. T. Okuyama, T. Fueno, and J. Furukawa, J. Polym. Sci., A-1, 6, 993, 1001 (1968).

7. T. Higashimura, T. Masuda, S. Okamura, and T. Yonezawa, J. Polym. Sci., A-1, 7, 3129 (1969).

8. K. Hatada, T. Hasegawa, T. Kitayama, and H. Yuki, J. Polym. Sci., Polym. Lett. Ed., 14, 395 (1976).

9. K. Matsuzaki, Y. Kanai, N. Morii, T. Higashimura, Y. Hirokawa, and Y. Fujiwara, Polym. Prepr., Jpn., 28 (No. 3), 372 (1979).

10. A. Mizote, T. Higashimura, and S. Okamura, $J$. Polym. Sci., A-1, 6, 1825 (1968).

11. J. R. Johnson, "Organic Reactions," Vol. 1, Wiley,
New York, N.Y., 1942, p 251.

12. T. Masuda and T. Higashimura, J. Macromol. Sci., Chem., A5, 547 (1971).

13. K. Matsuzaki, T. Uryu, T. Seki, K. Osada, and T. Kawamura, Makromol. Chem., 176, 3051 (1975).

14. T. Uryu and K. Matsuzaki, unpublished data.

15. D. M. Grant and E. G. Paul, J. Am. Chem. Soc., 86, 2984 (1964); C. J. Carman, A. R. Tarpley, Jr., and J. H. Goldstein, Macromolecules, 6, 719 (1973).

16. J. M. Rooney, Makromol. Chem., 179, 2419 (1978).

17. K. Yamamoto and T. Higashimura, Polymer, 17, 828 (1976). 